A R T I G O S

\title{
TRANSFORMAÇÕES NA LEGISLAÇÃO SESMARIAL, PROCESSOS DE DEMARCAÇÃO E MANUTENÇÃO DE PRIVILÉGIOS NAS TERRAS DAS CAPITANIAS DO NORTE DO ESTADO DO BRASIL
}

Changes in the land grants legislation, demarcation processes and maintenance of privileges in the "capitanias" of the North of Brazil

CARMEN MARGARIDA OLIVEIRA ALVEAL

Carmen Margarida Oliveira Alveal é professora adjunta do Departamento de História da Universidade Federal do Rio Grande do Norte (carmenalveal@uol.com.br).

Este trabalho contou com o apoio financeiro da Coordenação de Aperfeiçoamento de Pessoal de Nível Superior (Capes). Artigo recebido em 29 de junho e aprovado para publicação em 29 de setembro de 2015. 


\title{
Resumo
}

0 artigo analisa as transformações ocorridas na legislação sesmarial no reinado de D. Pedro II em Portugal (1683-1706) e as consequências dessas mudanças. A partir de 1690 houve tentativas de controle sobre as sesmarias, e várias ordens régias foram outorgadas para regular lacunas deixadas pelas Ordenações, referentes ao tamanho das sesmarias, à necessidade de demarcação e confirmação régia, mas principalmente para instituir o pagamento de um foro nas Capitanias do Norte do Estado do Brasil, modificando o estatuto jurídico da doação sesmarial. Além das ordens régias, analisamos relatórios de desembargadores, petições de moradores e consultas ao Conselho Ultramarino. Esse cruzamento de fontes nos permitiu perceber na prática essa tentativa de um maior controle das autoridades sobre a legislação sesmarial.

Palavras-chave: sesmaria, legislação, Brasil colonial, terra, privilégios, processos de demarcação.

\begin{abstract}
The article analyses the changes in the land grants legislation that occurred during the reign of D. Pedro II in Portugal (1683-1706) and their consequences. From 1690 on attempts were made to control land grants, and several royal charters were sanctioned in order to rule the gaps left by the Ordinances, concerning the size of the land grants, the necessity of demarcation and of royal confirmation, but above all to impose the payment of a tax in the "capitanias" (administrative divisions) of the North of Brazil, thus altering the legal status of the grants. In our analysis, besides a collection of royal rules, we have examined documents such as judges' reports, petitions and queries made to and by the Overseas Council. The crossing of such sources allowed us to testify this attempt of the authorities to increase their control over the land legislation.
\end{abstract}

KeY-WORDs: land grants, legislation, colonial Brazil, privileges, land, demarcation processes.

\section{RÉSUMÉ}

L'article analyse les changements dans la législation concernant la propriété de la terre vérifiés sous le règne de D. Pedro II au Portugal (1683-1706) et leurs conséquences. Depuis 1690 on a témoigné des efforts pour contrôler la concession de terres, et plusieurs décrets royaux ont été édités dans le but de régler les lacunes laissées par les Ordonnances en ce qui concerne les dimensions des concessions de terres, la nécessité de démarcation et de confirmation royale, mais surtout à fin d'imposer le payement d'un forum dans les provinces du Nord de l'Etat du Brésil, en altérant ainsi le statut juridique du don. Dans notre analyse, nous avons examiné les décrets royaux, mais aussi des rapports de juges, des pétitions de résidents et des requêtes présentées au Conseil d'Outre-Mer. Ces sources nous ont permis de mieux comprendre cet effort pour assurer un plus grand contrôle des autorités sur la législation.

Mots-CLÉ: législation, terre, Brésil colonial, privilèges, procédures de démarcation. 


\section{INTRODUÇÃO}

$\mathrm{O}$ processo de colonização e interiorização da América portuguesa transcorreu lentamente, sendo utilizado o sistema de sesmarias como forma principal de distribuição de terras. ${ }^{1}$ Tal sistema, pensado para resolver problemas de abastecimento em Portugal em $1375^{2}$ e utilizado na colonização do Atlântico, teve que ser aperfeiçoado à medida que novas situações eram apresentadas no decorrer da ocupação territorial. Os agentes da Coroa, tanto no reino quanto nas conquistas, discutiam as melhores soluções para dirimir problemas lacunares das Ordenações régias. É sabido que nos dois primeiros séculos da colonização as sesmarias foram distribuídas com extensas dimensões, fruto da própria falta de especificações nas Ordenações, ${ }^{3}$ mas também da visão de que, diante de tantas terras, não seria problema a cessão de gigantescas extensões.

Um projeto que se foi constituindo a partir da Restauração, com D. João IV (16401656), passou por Afonso VI (1656-1683), mas foi consolidado com D. Pedro II (1683-1706), como destacou Maria de Fátima Gouvêa (2001), sob o qual as conquistas na América passaram a receber mais atenção por parte das autoridades reinóis, formulou, no tocante às sesmarias, uma gama de ordens reais que passaram a regulamentar aspectos antes não contemplados pelas Ordenações. ${ }^{4}$ As novas diretrizes resultaram em uma tentativa ampla de regulamentação da posse de sesmarias em praticamente todas as capitanias, inclusive com a instituição de um foro anual, o que configurava uma mudança no estatuto jurídico das doações de sesmarias. Exceções, entretanto, permaneceram, evidenciando o caráter da sociedade de privilégios característica do Antigo Regime.

Este artigo pretende abordar dois aspectos: de um lado, as mudanças ocorridas na legislação sesmarial, sobretudo na década de 1690, as quais resultaram nos processos de demarcação e na cobrança de foro, situação vivenciada pelas chamadas Capitanias do Norte do Estado do Brasil, e, de outro, a manutenção de privilégios para aqueles que lutavam "bravamente" contra índios e negros, caso das tropas, principalmente do Terço dos Paulistas, que atuaram contra o Quilombo dos Palmares, bem como na chamada Guerra dos Bárbaros. 


\section{MUDANÇAS NA LEGISLAÇÃO SESMARIAL: A IMPLEMENTAÇÃO DO FORO E OS PROCESSOS DE DEMARCAÇÃO}

$\mathrm{N}$

a última década do século XVII, no reinado de Dom Pedro II, houve um aumento da regulação sobre o sistema sesmarial a partir da definição de limites máximos para as sesmarias e da consequente necessidade de diligências para verificar tanto seu tamanho quanto se haviam sido demarcadas, e principalmente se haviam sido aproveitadas ou com a agricultura ou com a pecuária. Entre as ordens régias mais importantes estavam a de 1697, que finalmente deliberava sobre o tamanho da terra, e a provisão de 1699, que estabelecia a cobrança de foro sobre as sesmarias das Capitanias do Norte do Estado do Brasil - esta última resultaria em inúmeros problemas, desde o processo demarcatório, passando pela questão da nomeação da autoridade responsável pela concessão das sesmarias, e culminando em conflitos de jurisdição e críticas quanto à atuação das autoridades coloniais que não cumpriam a nova orientação.

Antes da Ordem Régia de 27 de dezembro de 1697, o tamanho era relativo à capacidade de aproveitamento, ponto que já estava estabelecido nas Ordenações e foi confirmado no Regimento de Tomé de Souza. A nova lei estabeleceu a medida de 3 léguas de comprimento por 1 légua de largura nas áreas de agricultura, afirmando que essa seria a medida que um sesmeiro seria capaz de aproveitar.

Também em fins do século XVII, precisamente em 20 de janeiro de 1699, uma provisão dada pelo rei estabelecendo a cobrança de foro proporcionalmente ao tamanho que as sesmarias deveriam ter surgiu como primeira tentativa de controlar a terra, mediante a atribuição de um valor aferido por sua dimensão. Tal provisão foi endereçada ao governador da Capitania de Pernambuco, ${ }^{5}$ para as Capitanias do Norte sob sua jurisdição, ficando assim fora dessa regulamentação as Capitanias da Bahia e do Centro-Sul, bem como a região do Pará-Maranhão. Embora inicialmente não houvesse especificações do valor a ser cobrado pelos foros, essa provisão marcou o início de uma tentativa de aprimorar o controle sobre o sistema sesmarial. Varnhagen (1981: 265) aponta a cobrança do foro como uma possibilidade de limitar a extensão das sesmarias. De fato, a provisão data do mesmo quinquênio em que várias outras provisões trataram do tamanho das sesmarias. E até aquele momento as sesmarias tinham extensões muito largas, o que causou inúmeras reclamações de outros moradores e mesmo acusações de usurpação (Porto, 1965; Motta, 2008; Alveal, 2007). Assim, essa ordem régia era uma tentativa de limitar o tamanho das terras concedidas em sesmarias, ou seja, a cobrança de foro colocava-se como um limite "natural" à grande extensão, no sentido de que o ônus total que incidia sobre a sua doação acabava por tornar-se um custo não desejado pelos sesmeiros. 
Mais interessante é que quando o foro passou a ser cobrado houve uma mudança jurídica no estatuto do sistema sesmarial, alterando-se os direitos de propriedade anteriormente estabelecidos pela Coroa: uma vez que a concessão era condicionada ao usufruto da terra (Motta, 2008), do momento em que se passava a cobrar o foro sinalizava-se que a Coroa tinha o entendimento de que as terras the pertenciam e criava-se uma relação de enfiteuse (Porto, 1965), e não apenas uma mercê. Com isso modificavam-se temporariamente os direitos de propriedade relativos às sesmarias, cuja condição maior era o cultivo, e agora, no caso das Capitanias do Norte, passava a ser o pagamento do foro anual. Foi justamente essa mudança no entendimento dos direitos de propriedade sobre a sesmaria que provocou algumas incertezas nas autoridades coloniais ligadas diretamente à fiscalização e à concessão de sesmarias.

Apesar de a cobrança de foro ter enfrentado dificuldades inerentes à administração colonial, em alguns casos ela foi de fato perpetrada, sendo ratificada diversas vezes pela Coroa e pelas próprias autoridades coloniais. 0 primeiro problema suscitado pela nova medida referiu-se à sua aplicabilidade. Falava-se em cobrança embora não se tivesse estabelecido quem seria o agente dela encarregado. Assim, Fernando Martins Mascarenhas de Lencastro, Governador de Pernambuco, reuniu-se no Palácio das Torres em junta também composta pelo Bispo Francisco de Lima, o Ouvidor Geral Manoel da Costa Ribeiro e o Procurador da Coroa e Fazenda Antonio Rodrigues Pereira, e na reunião foi lida a provisão real datada de 20 de janeiro de 1699, expedida pelo Conselho Ultramarino.

A junta definiu que em toda légua de terra dada em sesmaria fosse estabelecido foro equivalente a seis mil réis em áreas cuja distância fosse de até 30 léguas do Recife, considerando-se a sua melhoria pela vizinhança da cidade. No caso de distância superior, o valor seria de quatro mil réis. Para assegurar a boa arrecadação dos ditos foros, previa-se nos títulos de sesmarias a verificação das confrontações, juntamente com a data em que foram feitas, de modo a possibilitar a cobrança do foro anual. 0 interessante é que se criou uma qualidade hierárquica relativa à distância do "centro" da capitania, pois para as autoridades o Recife era colocado como parâmetro. Não houve discussão sobre a produtividade da terra, ou algo semelhante, princípio fundamental da lei de sesmarias. Portanto, se a sesmaria era cultivada ou não ficou em segundo plano.

Os registros relativos a confrontações das terras eram enviados ao Governador e Capitão General de Pernambuco, o qual os remetia aos capitães-mores das freguesias e distritos em que haviam sido cedidas as datas. Depois de cobradas, deveriam ser encaminhadas ao almoxarife, espécie de tesoureiro real encarregado de cobrar os impostos, portanto responsável pela cobrança de foros na capitania de Pernambuco, ${ }^{6}$ que teria mais dois livros rubricados pelo provedor, os quais Ihe serviriam, um, escrito pelo seu escrivão da Receita, de relação dos 
que cobrar, e o outro, das despesas que se houvesse de fazer. No caso dos livros em que 0 provedor era o supervisor responsável, incluía-se o registro do pagamento dos novos direitos. ${ }^{7}$

Após definidos os valores do foro e quem os receberia, as demarcações ainda levaram um tempo para serem iniciadas. Somente em 3 de março de 1702 o Conselho Ultramarino ordenou que se procedesse às medições, bem como à verificação do cultivo das sesmarias em Pernambuco, e fez divulgar editais anunciando que sesmeiros e donatários deveriam apresentar suas confirmações e cartas em um prazo de seis meses. ${ }^{8}$ Os editais os notificavam, ainda, sobre o prazo de dois anos para demarcar as terras judicialmente. Alguns desembargadores foram nomeados para tratar das medições, o que significava que passavam a ter seus pagamentos vinculados ao pagamento feito pelos próprios sesmeiros pela demarcação, sendo o valor pro rata. ${ }^{9}$

Em 6 de junho de 1703, o desembargador da Relação da Bahia, João de Puga de Vasconcelos, foi indicado para proceder ao exame das terras "por se ter boa opinião das terras, inteireza e capacidade deste ministro e que nesta comissão se haverá muito conforme as obrigações da sua pessoa e ao que convém do serviço de Vossa Majestade" . ${ }^{10}$

Tal como no caso de outro desembargador, Cristovão Soares Reimão, nomeado para idêntica diligência nas Capitanias da Paraíba, Rio Grande e Ceará, sua remuneração era "ausentada" quando do embarque, passando ele a ser pago pelos próprios sesmeiros e donatários pro rata. Ademais, deveriam eles ser assistidos pelos capitães-mores e oficiais da câmara em toda ajuda que se fizesse necessária.

O fato de a remuneração do magistrado ser suspensa pela Coroa e imediatamente substituída por pagamentos realizados pelos próprios sesmeiros à proporção que suas terras fossem medidas é relevante para ilustrar o custo envolvido na demarcação de uma sesmaria, e igualmente importante para explicar o impedimento de parte da população que não poderia arcar com o ônus da demarcação, sendo assim impedida na prática de receber o documento oficial ou de ter acesso à terra. Não se deve descartar também a possibilidade de que alguns não quisessem de fato pagar, por preferir empregar o dinheiro em algo mais útil, ou se negassem por acreditar ser um abuso da parte da Coroa.

0 desembargador João de Puga de Vasconcelos procedeu à diligência, juntamente com o escrivão das sesmarias de Pernambuco, Damazo Saraiva de Araújo e mais alguns oficiais. Não se tem a data do início dessa diligência, mas seu relatório final é de 12 de janeiro de 1706. Ao final de sua jornada, João de Puga de Vasconcelos havia examinado de 44 léguas, cerca de 290 quilômetros, equivalentes a 63 sesmeiros. ${ }^{11}$

A realização da diligência revelou-se bastante árdua para essa autoridade colonial, e no próprio ano de 1706, em 30 de agosto, o desembargador escreveu ao Conselho Ultramari- 
no solicitando que não mais fosse nomeado para tal tarefa, principalmente por haver falta de pessoal na Relação da Bahia, onde pretendia voltar a servir. Entre as várias justificativas por ele apresentadas constava a distância, já que, em lugar de percorrer as supostas 14 léguas como se pensava inicialmente, andara muito mais para verificar os títulos possuídos pelos sesmeiros e confirmar se as sesmarias estavam ou não cultivadas. Alegava ele, principalmente, que o trabalho era áspero, oferecendo perigos diante dos vários achaques sofridos devido a acusações de que teria enriquecido nas jornadas. Finalizava sua carta queixando-se do clima e de que tinha cinco filhos de pouca idade. 0 Conselho considerou suas razões e o mandou servir novamente na Relação da Bahia. ${ }^{12}$

A partir da mencionada alegação de enriquecimento pessoal, pode-se perceber a reação dos moradores à obrigatoriedade do pagamento pela medição da terra ou mesmo ao valor que the era atribuído, por eles considerado demasiado alto. Não há registro do valor recebido pelo magistrado, nem se consistia em uma porcentagem sobre 0 arrecadado. ${ }^{13}$

O sistema de sesmarias nas Capitanias do Norte enfrentou outros problemas, como 0 de jurisdição responsável sobre quem poderia passar as cartas de concessão. Cabe lembrar que apenas a Capitania de Pernambuco tinha governador, estando as capitanias adjacentes submetidas ao seu poder no século XVIII (com exceção da Paraíba, que somente em 1756 passou a ser considerada anexa), embora fossem comandadas por capitães-mores que ora não tinham o direito de conceder cartas de sesmarias, ora o tinham, desde que as concessões viessem a ser reconfirmadas pelo Governo de Pernambuco (ou da Bahia) e, posteriormente, pela Coroa em Lisboa.

Contudo, nos anos de 1712 e 1713, o Governador de Pernambuco Felix José Machado trocou correspondência com o rei sobre a questão de quem deveria ser responsável pela concessão de cartas de sesmarias. A autoridade colonial registrava que os capitães-mores do Ceará e Rio Grande estavam emitindo provisões de ofícios e de alguns postos, bem como cartas de sesmarias, sem terem a devida jurisdição, segundo seus regimentos, cabendo-lhes tão somente prestar informação sobre as pessoas aptas a merecer tais nomeações e mercês, e competindo somente ao governador, como seu superior, concedê-las. ${ }^{14}$

Para manter a observância das ordens reais, Felix José Machado fez registrar nos livros de ambas as capitanias a resolução real. 0 rei agradeceu ao governador por informá-lo que a Fazenda Real estava tendo prejuízo diante de atuações como a dos capitães-mores do Rio Grande e Ceará, confirmando sua subordinação ao governador de Pernambuco, e finalizou sua carta ordenando que os capitães-mores se abstivessem de tal abuso. ${ }^{15}$

Ao longo do século XVIII a situação mudou com as ordens régias de 14 de dezembro de 1746, 7 de janeiro de 1752 e 22 de março de 1766, em que se confirmava que não cabia 
mais aos capitães-mores do Rio Grande submeterem-se à jurisdição do governador da Capitania de Pernambuco. ${ }^{16}$ Varnhagen (1981: 333-334) já aponta que em 1721 os capitães-mores passaram a ter maior importância, principalmente nas vilas e freguesias onde atuavam. De certa forma, na primeira metade do século XVIII os capitães-mores do Rio Grande e do Ceará concederam centenas de cartas de sesmarias que contribuiriam para a colonização.

Não foi somente nas áreas onde passou a existir a cobrança de foro sobre a terra que diligências para medição foram realizadas. Também na Bahia passou-se a executar a medição de terras. Em um primeiro momento, em 1703, o próprio Senado da Bahia solicitou a medição de suas terras, visando a saber quais seriam elas exatamente, além de verificar aquelas que estavam sendo ocupadas por posseiros. ${ }^{17} 0$ nomeado para a tarefa foi o desembargador José da Costa Correa, que, tal como nos casos antes mencionados, teria sua remuneração suspensa uma vez que esta seria paga com a própria tarefa de passar as cartas de sesmarias no momento em que a Câmara procedesse à redistribuição. 0 ministro seria acompanhado de escrivão, medidor, piloto e ajudante da Coroa. ${ }^{18}$ Este é o primeiro documento que faz referência ao cargo de piloto, aí entendido como piloto da terra, em contraposição ao piloto do mar ou de navio. Geralmente trazia uma corda a ser utilizada para as medições, tomando ainda acidentes naturais ou algumas construções, em casos de medição em áreas urbanas, como marcos delimitatórios. Contudo, anteriormente, sobretudo nas vilas, o mestre de campo era 0 responsável pela medição nas áreas urbanas (Abreu, 2005).

Assim, os primeiros anos do século XVIII, ainda no reinado de Dom Pedro II, evidenciam a tentativa efetivada pela Coroa de realizar processos de demarcação das sesmarias. Após esse procedimento de grande vulto, há registros de atos de demarcação e cobrança de foro nas Capitanias do Norte do Estado do Brasil somente 30 anos depois. Em 1739, o Governador de Pernambuco Henrique Luís Pereira Freire de Andrada queixava-se ao rei da desordem na cobrança do foro anual. ${ }^{19}$ Ele já havia informado ao rei anteriormente tanto sobre as irregularidades da cobrança da Real Fazenda quanto sobre os descuidos de almoxarifes e, principalmente, sobre a cobrança dos foros das sesmarias. Reclamava que se cobrava foro apenas das sesmarias próximas a Recife, ou seja, aquelas que deveriam pagar seis mil réis por légua. As do sertão, entretanto, que deveriam ser taxadas em quatro mil réis por légua, não estavam sendo cobradas. Logicamente, cobrar foro das que estavam ao redor de Recife era mais viável.

Nas diligências ordenadas pelo Governador Henrique Luís Pereira Freire de Andrada descobriu-se que a Fazenda Real estava tendo um enorme prejuízo. Meticulosamente, o governador apresentou todos os cálculos; denunciou que os capitães-mores da capitania do Ceará não estavam cobrando foro e, oferecendo números e operações matemáticas, alertou o rei de que desde 0 ano de 1699, início da cobrança de foro, haviam sido concedidas 923 sesmarias num 
total de 4.069 léguas, o que significava um prejuízo à Fazenda Real de cerca de 16:276\$000 réis por ano. Com base nesse cálculo, o governador de Pernambuco acreditava que as sesmarias deveriam ser registradas com urgência na Secretaria da Provedoria da capitania de Pernambuco, além de demarcadas e registradas em livros de suas capitanias, para que, ao serem confirmadas pelo governo de Pernambuco, fosse possível a cobrança do foro devido. ${ }^{20}$

Já que a capitania do Ceará encontrava-se sob jurisdição do governador de Pernambuco, em 1738 este enviou ordem ao capitão-mor do Ceará, Domingos Simões Jordão, determinando a imediata cobrança do foro. Porém, a despeito da ordem, foram passadas posteriormente 40 novas datas de sesmarias. Escrevendo ao rei mais uma vez, Henrique Luís Pereira Freire de Andrada pedia castigo exemplar ao capitão-mor por "faltar as ordens de Vossa Majestade, e a minha, e que ao menos seja obrigado a pagar da sua fazenda tudo que a de Vossa Majestade tem perdido por haver dado estas últimas datas depois de não poder alegar ignorância alguma que o releve de culpa".21

O governador de Pernambuco, contudo, reconhecia que a situação econômica da região era a pior possível diante de seu estado de pobreza e informava ao rei que os moradores encontravam-se praticamente impossibilitados de pagar o foro, dificultando a ação dos provedores e promovendo, assim, a "desordem" na colônia. Alertava ainda que, caso os próprios moradores quisessem vender as terras, não haveria quem as comprasse por falta de meios financeiros diante das dificuldades de recursos na região.

Mas a sua preocupação centrava-se nas terras não ocupadas. A solução apresentada por esta autoridade foi a de lançar editais ao som de caixas, ${ }^{22}$ junto a todas as freguesias, para que as pessoas providas de sesmarias ou quaisquer terras e ainda engenhos apresentassem os títulos diante do ouvidor da capitania no prazo de dois anos. Caso não o fizessem, tais terras seriam consideradas devolutas - na acepção original, devolvidas ao rei. Após o ouvidor examinar e emitir seu parecer ao governador, finalmente seriam concedidas as cartas de confirmação, mediante imposição do pagamento do foro anual à provedoria da capitania onde estivessem situadas. Ao apresentar soluções, o governador mostrava que as autoridades coloniais não eram apáticas e passava a responsabilidade do provedor para o ouvidor. ${ }^{23}$

Seguia-se, ainda, o princípio de que as sesmarias concedidas deveriam ser cultivadas em três anos, como no regimento, demonstrando que se havia povoado as terras, e de que nos dois anos seguintes os sesmeiros seriam obrigados a mostrar a confirmação real. As sesmarias que não tivessem sido povoadas nem confirmadas dentro de cinco anos tornar-se-iam devolutas. As cartas concedidas pelos capitães-mores das capitanias adjacentes deveriam ser registradas na Secretaria da Provedoria de Pernambuco, pagando-se por esse registro, e as já passadas deveriam pagar ao menos uma taxa para os oficiais (Alveal, 2007). 
Contudo, o Conselho Ultramarino, em setembro do mesmo ano de 1739, descartou o parecer do governador, afirmando que as imposições de foro não deviam ser executadas, uma vez que a carta de 20 de janeiro de 1699, estabelecendo a cobrança de foro, não estava compreendida no Regimento Geral do governo do Brasil, dado a Tomé de Souza, além de fugir das concepções de povoação formuladas no tempo do rei D. João III. Tampouco estariam contempladas na Ordenação do Reino que dispunha em favor da cultura, e por "Razão da validade pública se reprova todo o foro ou tributo que se impuser de novo nas sesmarias, e pondo se este, seja nulo e de nenhum efeito, ficando a sesmaria em seu vigor, e sem a tal obrigação". ${ }^{24}$ Assim, o Conselho Ultramarino recuperava as condições originais do sistema sesmarial baseadas no aproveitamento da terra.

0 Conselho ainda considerava que as despesas realizadas para manter as sesmarias e criar o gado eram extremamente altas, já que era comum que o gado morresse, tornando-se intolerável um novo tributo. Assim, o próprio Conselho Ultramarino considerava as despesas altas para os sesmeiros e reiterava a informação das dificuldades econômicas dos sesmeiros da região. ${ }^{25}$

Foi a primeira vez que o Conselho Ultramarino descartou a cobrança de foro, embora em nenhum momento a Coroa tenha revogado a provisão de 1699, o que continuaria a ser como um problema para as autoridades coloniais que tentavam seguir determinações anteriores. Dessa forma, apesar de não revogado, o foro não foi cobrado por alguns anos, até que novamente outro governador trouxesse à tona a provisão de 1699 e levantasse os mesmos problemas. Interessante notar que, ao negar a provisão de 1699, o Conselho enfatizava que a legislação sesmarial se limitava às Ordenações e ao regimento, reforçando a noção do cultivo como princípio. ${ }^{26}$

A prática de não se cobrar foro desagradava a algumas autoridades, que insistiam na necessidade de cumprir a legislação. Em 1741, o governador de Pernambuco escrevia ao secretário de estado de Marinha e Ultramar, Antonio Guedes Pereira, e reclamava que os sesmeiros não pagavam foros, como também não estava sendo imposta a obrigação de povoarem as terras, já que sempre se esperava o perdão da "real piedade" para quem não tivesse pagado o foro. ${ }^{27}$

\section{A MANUTENÇÃo DE PRIVILÉGIOS}

$S$ e de um lado houve a tentativa de uma melhor regulamentação no tocante à terra no período de D. Pedro II, por meio de um conjunto de ordens régias complementares que impunham a limitação do tamanho e a cobrança do foro, de outro lado verificou-se a manu- 
tenção de privilégios, característica da sociedade do Antigo Regime transplantada para as conquistas, no sentido de garantir a concessão de isenções àqueles que serviam à Coroa. Caso clássico da história das Capitanias do Norte foi não somente a concessão de terras aos chamados conquistadores dos Palmares: além da cessão das terras "conquistadas", eles ficaram isentos do foro que se impunha aos "simples" moradores dessas capitanias. Tal isenção foi também solicitada pelo Terço dos Paulistas envolvido na Guerra dos Bárbaros na região do Assu (Silva, 2015).

Dessa forma, ao mesmo tempo que se efetuou essa tentativa de maior controle por parte da Coroa e das autoridades coloniais sobre as sesmarias, e sobre o acesso à terra em geral, por meio das ordens régias complementares e dos processos de demarcação ocorridos, percebe-se também a questão da manutenção da política de remuneração por serviços prestados à Coroa em forma de privilégios sobretudo aos conquistadores. 0 Terço dos Paulistas e os privilégios que recebiam por suas atividades contribuíram assim para criar diferença no estatuto da posse da propriedade sesmarial. Uma vez que os chamados "conquistadores de Palmares" recebiam sesmarias, poderiam estar sujeitos às ordens régias que passariam a regular o tamanho e o foro, mas o que aconteceu foi o estabelecimento da isenção da cobrança do foro a esse grupo e a seus descendentes.

Essas isenções, entendidas como privilégios, foram também objeto de discussão ao longo do século XVIII. Assim, em 1757, décadas após a guerra de Palmares, o capitão da região do antigo Quilombo dos Palmares, Simão Alves de Vasconcelos, pediu ao rei D. José I certidão das ordens referentes às datas de sesmarias. ${ }^{28} \mathrm{~A}$ questão de Palmares suscitou algumas discussões. Primeiro, pelos que foram combatidos e destroçados, pois existe um documento do rei obrigando as autoridades a cederem terras àqueles negros que quisessem cultivar. ${ }^{29}$ Por outro lado, Palmares representou a primeira grande empreitada de distribuição de terras como recompensa por participação em campanhas militares, assim como a Guerra dos Bárbaros, empreendida contra os índios quase que simultaneamente (Puntoni, 2002; Silva, 2015). Todos os combatentes, das mais altas patentes às mais baixas, tiveram direito a um quinhão de terra, variando o tamanho de acordo com o posto. ${ }^{30}$ Além disso, foram agraciados com outras regalias, tais como o não pagamento de pensões. Nesta esfera, a legislação apresenta-se contraditória, além de a administração colonial revelar atritos com a Coroa.

Por volta de 1759-1760, Duarte Ramos Furtado e seu irmão José da Cunha, ambos alferes de Infantaria da guarnição do Palmar, requereram ao governador de Pernambuco que os isentasse de pagar o foro de quatro mil réis por cada légua de terra, das duas que haviam herdado de seu falecido pai, João Gonçalves Furtado, um dos chamados "restauradores", 
o que havia sido determinado para a Capitania de Pernambuco. Alegavam que, como descendentes dos "restauradores do referido Lugar", entre os quais foram repartidas as terras da região sem a pensão anual, mas somente dízimo, teriam direito à isenção. 0 governador argumentava que a isenção das relativas datas concedida pela ordem régia era somente aos conquistadores originários, não se ampliando aos seus sucessores. ${ }^{31}$

A decisão das autoridades metropolitanas, contrária à do governador, foi que se concedesse a sesmaria, já que eram descendentes de "Restauradores de Palmar", livres de toda pensão, e com encargo somente de pagar dízimos. Novamente a Coroa foi benevolente com seus súditos, enquanto as autoridades coloniais tentavam ser mais rígidas na aplicação das leis, mostrando como havia uma preocupação com o interesse da Coroa, que era a ocupação das terras para que houvesse rendimentos que chegassem à Fazenda Real.

0 governador refutou a decisão, respondendo e inclusive anexando a ordem régia de 1703. Defendia que a isenção dada somente aos conquistadores originários não devia ser estendida no tempo - afinal tratava-se de 1759 -, beneficiando seus descendentes. Repetiria 0 mesmo argumento ainda em uma outra denúncia, em 1761. Em resposta, os irmãos alegavam que mesmo 70 anos após, ainda se passavam cartas de sesmaria naquela área, como foi 0 caso de Simão Alves de Vasconcelos, sem pensão de foro.

Não se sabe como terminou o caso, mas de fato Simão Alves de Vasconcelos, capitão de infantaria de Palmares, iniciou um processo de sesmaria. Contudo, inteligentemente, requereu uma cópia da carta régia de 28 de janeiro de 1698 que regulava a quantidade de terras a serem dadas aos participantes da guerra em Palmares de acordo com sua patente. 0 governador Luís José Correa de Sá concedeu a carta de doação em 1755 com isenção de foro, regalia requerida pelos irmãos do documento anterior. Dois anos após, a carta de confirmação de Vasconcelos foi deferida. ${ }^{32}$

\section{CONCLUSÃO}

multiplicidade de agentes e agências envolvidos na concessão, regulação e validação
de sesmarias - como governadores, provedores, capitães-mores, almoxarifes e escrivães, além do Conselho Ultramarino e das provedorias locais - contribuiu para a deflagração de inúmeros conflitos de interesses, já que a própria concessão de mercês estabelecia relações interpessoais e uma camuflada troca de conveniências em um jogo político que, muitas vezes, se explicitava abertamente. ${ }^{33}$ Os conflitos envolviam hierarquias diferentes, desde agentes localizados na Corte e na colônia, até autoridades coloniais localizadas nos principais núcleos urbanos ou mesmo em localidades distantes do litoral. 
0 período de 1690, década na qual várias ordens régias tentavam preencher lacunas ou mesmo complementar a legislação sesmarial, assistiu ao início de vários processos de demarcação, bem como a cobrança do foro nas Capitanias do Norte do Estado do Brasil. Essas ordens régias, e a tentativa de sua aplicação, evidenciam as transformações jurídicas ocorridas na legislação sesmarial, sobretudo no período de D. Pedro II de Portugal, e as consequências dessas mudanças. Apesar de haver estudos mostrando como a legislação durante o período pombalino teria acarretado uma centralização política, o estudo proposto evidenciou, no tocante à questão da terra, que houve tentativas de um maior controle sobre o acesso à terra a partir de 1690, que prosseguiram no período joanino.

Ao focalizar a questão dos impostos incidentes sobre o sistema sesmarial - relativos à concessão, demarcação e confirmação de terra -, a pesquisa verificou que todas as etapas envolviam o pagamento de quantias que assegurassem o "direito" ao cumprimento da legislação, como é o caso do registro na Chancelaria, podendo eles ser considerados como empecilhos a seu próprio cumprimento, no sentido de que as exigências burocráticas do processo eram onerosas e trabalhosas - caso da demarcação mas também do registro. Para as Capitanias do Norte, tal quadro agravar-se-ia ainda mais com a instituição da cobrança de foro. Esses aspectos aqui tratados mostram a burocracia para legalizar uma doação de sesmaria, além do custo financeiro enfrentados pelos sesmeiros, reforçando a convicção de que obter uma sesmaria e "mantê-la" legalizada representava investimentos que somente poucos puderam e quiseram fazer.

Se por um lado houve essa maior tentativa de controle régio, por outro, novos privilégios foram criados. Foi o caso da isenção de pagamento de foro aos membros do Terço dos Paulistas, mostrando o traço marcante de atuação da Coroa ao reforçar privilégios, corroborando uma hierarquização da sociedade colonial, similar às características da sociedade de Antigo Regime.

\section{NotAs}

1 Sobre as sesmarias, ver os dois principais estudos de juristas: os de Rui Cirne Lima (2002) e Costa Porto (1965). Entre sociólogos e historiadores, destacam-se estudos sobre a Lei de Terras de 1850 que abordam 0 sistema sesmarial, como os de Silva (1996) e Motta (2008).

20 estudo de Virgínia Rau (1982), As sesmarias medievais portuguesas, analisa a origem do sistema no período medieval português e mostra como a peste negra e outros fatores provocaram crises de fome, levando a Coroa a implementar o regime sesmarial para fomentar a produção agrícola. Já Armando Castro (1964) afirma que a legislação sesmarial seria uma forma de maior controle sobre a terra por parte daqueles que efetivamente a poderiam cultivar, alijando o campesinato. 
3 Ademais, registra-se que, no reino, as sesmarias eram distribuídas por sesmeiros membros da municipalidade, sendo seis os sesmeiros para regular as terras no termo, enquanto na América portuguesa eram os governadores ou capitães-mores, junto com provedores, que assumiam esse papel para as capitanias, sendo que as dimensões territoriais eram muito maiores do que os termos de vilas.

4 Ressalte-se também a vitória dos moradores de Pernambuco e das capitanias vizinhas sobre os holandeses, fortalecendo os laços de vassalagem entre o reino e essas regiões (Mello, 2007).

50 Governador Geral e também governador da capitania da Bahia, Dom João de Lencastro, recebeu uma carta mencionando exatamente o mesmo assunto, mas também se referindo à cobrança de foro nas áreas de Pernambuco. Alguns autores, como Nelson Nozoe (2006; 2014), Rui Cirne Lima (2002) e Costa Porto (1965), apresentam essa ordem régia como se ela tivesse sido aplicada em todo o Estado do Brasil. Entretanto, a pesquisa constatou que apenas as Capitanias do Norte ficaram sujeitas a ela. 0 porquê de apenas essa região ter ficado vinculada ao foro ainda não foi possível verificar. Caso se pense em uma tentativa de reduzir as posses dessa área, cabe mencionar que em todas as capitanias havia sesmarias com extensões exageradas, não sendo especificidade das Capitanias do Norte do Estado do Brasil.

6 Carta régia (cópia) do rei [D. Pedro II] a Fernão Martins Mascarenhas de Lencastro [governador da capitania de Pernambuco] ordenando a continuidade da cobrança dos foros às pessoas que receberam sesmarias, 28 de setembro de 1700. AHU - Pernambuco, Papéis Avulsos, Cx 19, Doc 1845.

7 Sobre o imposto dos novos direitos e as sesmarias, ver Alveal (2007: 164).

8 A obrigação de mostrar títulos alcançou praticamente todas as capitanias (Rio de Janeiro, São Paulo e Minas Gerais), apesar de a ordem régia sobre o foro legislar somente sobre as Capitanias do Norte. AHU - Códice 263, fl. 196; AHU - Códice 224, fl. 96v; e AHU, Códice 224, fl. 273.

9 Apesar de se saber que o valor era proporcional ao trabalho da demarcação, não foram encontrados os valores dessa proporção. Consulta do Conselho Ultramarino ao rei D. João V sobre o procedimento do desembargador João de Puga e Vasconcelos no tombamento das sesmarias e datas de terras da capitania de Pernambuco, 4 de novembro de 1706. AHU - Pernambuco, Papéis Avulsos, Cx 22, Doc 2027.

10 Idem.

11 Idem.

12 Idem.

13 Idem.

14 Carta de 9 de julho de 1713, in Carta (1 ${ }^{a}$ via) do [governador da capitania de Pernambuco] Félix José Machado [de Mendonça Eça Castro e Vasconcelos] ao rei [D. João V], 9 de setembro de 1713. AHU - Pernambuco, Papéis Avulsos, Cx 25, Doc 2304.

15 Carta de 23 de julho de 1713 in Carta (1 ${ }^{\text {a }}$ via) do [governador da capitania de Pernambuco] Félix José Machado [de Mendonça Eça Castro e Vasconcelos] ao rei [D. João V], 9 de setembro de 1713. AHU - Pernambuco, Papéis Avulsos, Cx 25, Doc 2304.

16 Provisão (cópia) do rei [D. João V] ordenando se conserve os corpos da Cavalaria da Ordenança, e que os postos, ofícios e datas de sesmarias, no Ceará e Rio Grande, não devem ser providos pelos capitães-mores, sem a obrigação de pedirem confirmação, 17 de agosto de 1740. AHU - Pernambuco, Papéis Avulsos, Pernambuco, Cx 56, Doc 4832. 
17 Existem diversos documentos que mostram medições sendo feitas em outros lugares além das Capitanias do Norte e da própria Bahia: AHU, Códice 97, fl. 287v - 288; AHU, Códice 241, fl. 321; AHU, Códice 242, fl. $20-20 v$; entre muitos outros.

18 Consulta do Conselho Ultramarino ao rei D. Pedro Il sobre a carta dos oficiais da Câmara da Bahia em que estes pedem provisão para que o governador-geral do Brasil Rodrigo da Costa nomeie um ministro da Relação para fazer a medição das terras que por sesmaria pertencem ao Senado, 7 de fevereiro de 1704. AHU - Bahia, Papéis Avulsos, Cx 4, Doc 51; Consulta do Conselho Ultramarino ao rei D. Pedro II sobre se encarregar ao desembargador José de Costa Correia a diligência de examinar as datas e confirmações das sesmarias de terras da capitania da Bahia, 5 de março de 1704. AHU - Bahia, Papéis Avulsos, Cx 4, Doc 56.

19 Carta do [governador da capitania de Pernambuco] Henrique Luís Pereira Freire de Andrada ao rei [D. João V], 12 de dezembro de 1739. AHU - Pernambuco, Papéis Avulsos, Cx 55, Doc 4769.

20 AHU - Bahia, Papéis Avulsos, Cx 4, Doc 56.

210 governador Henrique Luís Pereira Freire de Andrada acusava também o desembargador Cristovão Soares Reimão, o mesmo que tinha feito a diligência na Paraíba, Rio Grande e Ceará, de não ter registrado as ordens no Livro da Fazenda, confrontando-o. Dizia ainda que não havia sido possível averiguar o procedimento da cobrança de foro na Capitania do Rio Grande. Carta do [governador da capitania de Pernambuco] Henrique Luís Pereira Freire de Andrada ao rei [D. João V]. AHU -Pernambuco, Papéis Avulsos, Cx 55, Doc 4769.

22 Em geral, esses editais eram anunciados ao "som de caixas", o que significa que uma autoridade colonial juntamente com outro funcionário, este de posse de algum instrumento como um tambor, anunciavam em voz alta a temática do edital. 0 alcance provavelmente era mínimo, já que se restringia principalmente aos núcleos urbanos.

23 AHU - Bahia, Papéis Avulsos, Cx 4, Doc 56.

24 Carta do [governador da capitania de Pernambuco] Henrique Luís Pereira Freire de Andrada ao rei [D. João V]. AHU - Pernambuco, Papéis Avulsos, Cx 55, Doc 4769.

25 Idem.

26 Isso é interessante, pois parece até que o Conselho Ultramarino não sabia que existia essa prática e quando "descobriu" a tratou como algo não oficial, já que não estava no regimento. Pode-se até refletir um pouco sobre como, de um governante para o outro (de Pedro II para João V) ou entre os membros do conselho, a percepção da administração das posses ultramarinas se modificava de forma significativa.

27 Ofício do [governador da capitania de Pernambuco] Henrique Luís Pereira Freire de Andrada ao [secretário de estado da Marinha e Ultramar] Antônio Guedes Pereira, 29 de agosto de 1741. AHU - Pernambuco, Papéis Avulsos, Cx 57, Doc 4899.

28 Requerimento do capitão dos Palmares Simão Alves de Vasconcelos ao rei [D. José I] pedindo certidão das ordens referentes às datas de sesmarias, 26 de fevereiro de 1757. AHU - Pernambuco, Papéis Avulsos, CX. 82, Doc. 6878.

29 Carta do governador da capitania de Pernambuco, Aires de Sousa de Castro, ao príncipe regente [D. Pedro] sobre os negros dos Palmares que resolveram prestar obediência à Coroa e receberam terras de sesmarias. Este documento está bastante deteriorado. Em seu final aparece claramente que o governador de Pernambuco escreveu ao Conselho, em 8 de agosto de 1679, sobre o negros dos Palmares e suas famílias para os quais 
se haviam dado terras, porém mais nada se infere do documento infelizmente. 8 de agosto de 1679. AHU Pernambuco, Papéis Avulsos, Cx. 12, Doc. 1144.

30 Ordem Régia de 14 de junho de 1703.

31 Requerimento dos alferes Duarte Ramos Furtado e seu irmão José da Cunha ao rei [D. José I] pedindo para receber as sesmarias em Palmar com dispensa da pensão por serem descendentes dos restauradores do dito lugar, 11 de janeiro de 1760. AHU - Pernambuco, Papéis Avulsos, Cx. 93, Doc. 7376.

32 Requerimento do capitão dos Palmares Simão Alves de Vasconcelos ao rei [D. José I] pedindo certidão das ordens referentes às datas de sesmarias. AHU - Pernambuco, Papéis Avulsos, Cx. 82, Doc. 6878.

33 A autora mostra nos capítulos 7 e 8 de sua tese de doutorado (2007) como a aproximação de alguns potentados com ocupantes de cargos na justiça os favorecia. Também Francisco Eduardo Pinto (2014) analisa essa aproximação em busca de favorecimento no processo de povoamento das Minas Gerais.

\section{REFERÊNCIAS BIBLIOGRÁFICAS}

ABREU, Maurício de. Reencontrando a antiga cidade de São Sebastião: mapas conjeturais do Rio de Janeiro do século XVI. Cidades, São Paulo, v. 2, n. 4, 2005.

ALVEAL, Carmen Margarida Oliveira. Converting land into property in the Atlantic Portuguese world. Tese (Doutorado em História), Johns Hopkins University. Baltimore, 2007.

CAMARINHAS, Nuno. Juízes e administração da Justiça. Portugal e o Império Colonial. Lisboa: Fundação Calouste Gulbelkian/FCT, 2010.

CASTRO, Armando. A evolução econômica de Portugal dos séculos XII a XV. Lisboa: Portugália, 1964.

DIAS, Patrícia de Oliveira Dias. 0 tirano e digno Cristóvão Soares Reimão: conflito de interesses locais e centrais nas capitanias de Itamaracá, Ceará, Paraíba e Rio Grande no final do século XVII e início do XVIII. Revista Ultramares, v. 1, n. 11, 2012.

GOUVÊA, Maria de Fátima Silva. Poder político e administração na formação do complexo atlântico português (1645-1808). In: FRAGOSO, João; BICALHO, Maria Fernanda; GOUVÊA, Maria de Fátima (orgs.). 0 Antigo Regime nos Trópicos: a dinâmica imperial portuguesa (séculos XVI-XVIII). Rio de Janeiro: Civilização Brasileira, 2001.

LIMA, Rui Cirne. Pequena história territorial do Brasil: sesmarias e terras devolutas. Goiânia: Editora UFG, 2002.

MELLO, Evaldo Cabral de. Olinda restaurada. Guerra e açúcar no Nordeste 1630-1654. São Paulo: Editora 34, 2007.

MOTTA, Márcia. Nas fronteiras do poder. Conflito e direito a terra no Brasil do século XIX. 2a ed. revista e ampliada. Niterói: EDUFF, 2008.

NOZOE, Nelson. Sesmarias e apossamento de terras no Brasil Colônia. Economia, v. 7, n. 3, set/out 2006, pp. 587-605. 2014.

. A aplicação da legislação sesmarial em território brasileiro. Estudios Historicos, año Vl, n. 12, julio 
PINTO, Francisco Eduardo. A hidra de sete bocas. Sesmeiros e posseiros em conflito no povoamento das Minas Gerais (1750-1822). Juiz de Fora: Editora da UFJF, 2014.

PORTO, Costa. Estudo sobre o sistema sesmarial. Recife: Imprensa Universitária, 1965.

PUNTONI, Pedro. Guerra dos Bárbaros: povos indígenas e a colonização do sertão nordeste do Brasil. São Paulo: Hucitec, 2002.

RAU, Virgínia. Sesmarias medievais portuguesas. Lisboa: Presença, 1982.

SILVA, Ligia Osorio. Terras devolutas e latifúndio (efeitos da Lei de 1850). Campinas: Editora da Unicamp, 1996.

SILVA, Tyego Franklim da. A ribeira da discórdia: terras, homens e relações de poder na territorialização do Assu Colonial (1680-1720). Dissertação (Mestrado em História), Universidade Federal do Rio Grande do Norte, 2015.

SOUZA, Laura de Mello e. Os desclassificados do ouro: a pobreza mineira do século XVIII. Rio de Janeiro: Graal, 1982.

SUBTIL, José. Dicionário dos desembargadores, 1640-1834. Lisboa: EDIUAL, 2010.

VARNHAGEN, Francisco Adolfo de. História geral do Brasil: antes de sua separação e independência de Portugal. 10ª ed. Belo Horizonte/São Paulo: Ed. Itatiaia/EDUSP, 1981. 